\title{
Appraisal of CO2 Emission in Tunisia's Industrial Sector: A Dynamic Vector Autoregression Method
}

\section{Besma Talbi}

University of Carthage: Universite de Carthage

Muhammad Ramzan ( $\sim$ ramzanmehar7@gmail.com )

Shandong University of Finance and Economics https://orcid.org/0000-0001-7803-7960

\section{Hafiz Arslan Iqbal}

Shandong University of Finance and Economics

\section{Buhari Doğan}

Suleyman Demirel University

\section{Research Article}

Keywords: Industrial sector, Carbon dioxide emissions, Vector autoregressive model, Tunisia

Posted Date: September 3rd, 2021

DOl: https://doi.org/10.21203/rs.3.rs-659869/v1

License: (9) This work is licensed under a Creative Commons Attribution 4.0 International License. Read Full License

Version of Record: A version of this preprint was published at Environmental Science and Pollution Research on January 26th, 2022. See the published version at https://doi.org/10.1007/s11356-022$18805-y$. 


\section{Appraisal of $\mathrm{CO}_{2}$ Emission in Tunisia's Industrial Sector: A Dynamic Vector} Autoregression Method

\section{Besma Talbi,}

1. Polytechnic school of Tunisia, University of Carthage, Tunisia.

Email: besmatalbi@yahoo.fr

\section{Muhammad Ramzan*,}

2. Shandong University of Finance and Economics, Faculty of International Economics and Trade, 250014, Jinan, Shandong, China. Email: ramzanmehar7@gmail.com ORCID: http://orcid.org/0000-0001-7803-7960

*Correspondence Author

\section{Hafiz Arslan Iqbal}

3. Shandong University of Finance and Economics, Faculty of International Economics and Trade, 250014, Jinan, Shandong, China.

Email: arslaniqbalmughal@yahoo.com

\section{Buhari Doğan}

4. Suleyman Demirel University

Turkey

doganbuhari@gmail.com

ORCID: https://orcid.org/0000-0003-0655-4699 


\section{Abstract}

The World is confronted with a slew of environmental issues, one of which is how to attenuate the detrimental impacts of $\mathrm{CO}_{2}$ emissions-induced climate change. The ever-increasing use of energy is eroding natural resources to the point that our economic future may be jeopardized. The Tunisian economic growth indicates the excellent performance in the industrial sector as the minimum required input for these developments necessitates additional energy consumption, resulting in increased $\mathrm{CO}_{2}$ emissions and environmental degradation. This study explores the role of energy efficiency, urbanization, economic growth, and natural gas energy usage in the industrial sector on carbon dioxide $\left(\mathrm{CO}_{2}\right)$ emissions of Tunisia. The research mainly employs the Vector Autoregressive Model (VAR) to examine the factors driving the evolution of $\mathrm{CO}_{2}$ emissions through the industrial sector from 2000 to 2018. The findings assess that natural gas as an energy source and efficiency are crucial for reducing $\mathrm{CO}_{2}$ emissions. The study has shown the existence of the Environmental Kuznets Curve (EKC), which demonstrates that economic development in Tunisia has an inverted U-shape connection with $\mathrm{CO}_{2}$ emissions. The results indicate that energy consumption and GDP significantly affect $\mathrm{CO}_{2}$ emissions due to large-scale population movements and industrial structure transformation. In contrast, energy efficiency plays a dominant role in decreasing $\mathrm{CO}_{2}$ emissions. The article will assist economic decision-makers and related authorities in formulating an appropriate energy policy for the industrial sector based on the study's outcomes to protect environmental degradation in the long run by reducing carbon emissions.

Keywords: Industrial sector, Carbon dioxide emissions, Vector autoregressive model, Tunisia.

\section{Introduction}

Oil is the World's most abundant energy source, accounting for roughly $33 \%$ of worldwide energy use (Rapier, 2020). According to International Energy Agency, the industrial sector is the most energy-intensive, participating in 54\% of global energy consumption. Since 2010, energy consumption in the industry has upsurge by an average rate of $0.9 \%$ per year, dominantly a substantial rise of $1.6 \%$ in 2017 (IEA, 2020). In Tunisia, the industry is the second most energyintensive sector, sharing more than a third of overall energy consumption (Jain, 2018). The

62 industrial sector is incredibly reliant on fossil fuels, including natural gas, petroleum, and liquefied 
Tunisia have been steadily increasing since 1990, the World's overall industry accounts for roughly

$6521 \%$ of all emissions (Pachauri \& Meyer, 2014). The country has lowered its energy usage due to initiatives in energy efficiency to reducing greenhouse gas emissions. The utilization of mixed power and heat plants has been streamlined putting into action by the Tunisian central monitory system (IRENA et al., 2018). The country's representatives have advanced the expertise of industrial energy towards sustainable and efficient usage; still, this sector emitted around 32.1 million tonnes of CO2 in 2019 (CAIT, 2020). Historically, carbon emissions from manufacturing industries have fluctuated significantly in recent years, with a prominent upward trend from 1995 to 2014, reaching $21.3 \%$ in 2014 (KNOEMA, 2016). It prompts various researchers to focus on the driven roots behind the emitting $\mathrm{CO} 2$ emissions in the sector. In the context of literature, different methodologies have been undertaken to determine the driving elements of $\mathrm{CO}_{2}$ emissions of the industrial sector. For example, to study $\mathrm{CO}_{2}$ emissions in heavy industry, $\mathrm{Xu} \& \mathrm{Lin}$ (2020) utilized a quantile regression model and exposed that economic expansion at the provincial level significantly impacts $\mathrm{CO}_{2}$ emissions from heavy industry in the 25th to 50th quantile. On the other hand, urbanization has a more negligible impact on carbon emissions in the 10th to 25 th lower quantile provinces than the other quantile provinces. Song et al. (2018) investigated the $\mathrm{CO}_{2}$ emissions from China's steel industry by employing the index decomposition approach. As per the findings, economic $\mathrm{CO}_{2}$ emissions rise (Adebayo et. al., 2021). development boosted demand for these industrial products, resulting in increased carbon emissions from steel manufacturers. They further stated that maximizing energy intensity reduction and upgrading manufacturing technologies that optimize the energy structure have aided in limiting Moreover, Du \& Lin (2018) employed the log-mean Divisia index approach to investigate $\mathrm{CO}_{2}$ emissions in China's metallurgical industry. The findings uncovered that energy intensity and labor productivity have an adverse effect on carbon emissions, but industrial size positively impacts $\mathrm{CO}_{2}$. Wen et al. (2019) investigated the linkages between the Chinese steel industry and carbon emissions, recommending that renewable energy and carbon recycling techniques are the most effective way to reduce $\mathrm{CO}_{2}$ emissions in the long run in China. The study also quantified that regulating excessive expansion in the industrial sector is a key aspect in efficiently reducing carbon emissions. Tan et al. (2019) found similar results and suggested that curbing unauthorized industrial growth would be a substantial source to mitigate carbon emission. Another critical 
research examined the impact of carbon emissions from China's power business and discovered the intensive use of coal in the power industry contributes to carbon emissions (Meng et al., 2017). The study also tells that coal usage improves power generation efficiency in the long run. However, Chebbi (2010) used ARDL and ECM methods and reports the interaction between energy consumption, economic growth, and environmental degradation varies by industry with no uniform connectedness across several sectors in Tunisia.

In the same way, Farhani et al. (2014) discovered a long-term and solid causal association between carbon emissions, economic growth, and trade through the ARDL approach. Engo (2021) recently examined that economic growth and energy consumption played a crucial role in decoupling sectoral carbon emissions in Tunisia and Morocco. Some scholars also used the VAR model to measure the dynamic connectivity of carbon emission with energy consumption and economic growth. For instance, Xu \& Lin (2016) employed the VAR approach to estimate emissions from China's steel industry and found the natural gas usage is crucial to minimize carbon emissions. Dong et al. (2018) arrived at the same conclusion and validated the existence of EKC in the relationship between economic growth and carbon emissions.

The industrial sector occupies the second place of energy consumption in Tunisia; it represents more than a third of the total energy consumption (Safdar, 2020). The consumption of natural gas increased between 2000 and 2012 (more than 6\% per year) and remained stable until 2014. However, it increased by $3.4 \%$ per year compared to 2015 and stood at $65 \mathrm{bcm}$ in 2018 (Abid, 2020). The primary gas market remained of electricity production $67 \%$ in 2018 . In the same year, the total energy consumption of natural gas in the industrial sector was 907 ktoe (IAEA, 2018). In 2014, the manufacturing industries' $\mathrm{CO}_{2}$ emissions for Tunisia were around $21.3 \%$. However, the country's $\mathrm{CO}_{2}$ emissions have fluctuated considerably in recent years, and it tended to increase during the period 1995-2014, ending at 21.3\% in 2014 (ANME, 2019). In 2019, the $\mathrm{CO}_{2}$ emissions per capita for Tunisia were 2.72 tonnes of $\mathrm{CO} 2$ per capita. It grew with the rate of 0.84 tonnes of $\mathrm{CO}_{2}$ per capita to 2.72 tonnes from 1970-2019, increasing at an average annual rate of $2.52 \%$ (World Bank, 2020).

Energy efficiency is a way to reduce energy consumption and help companies to reduce their production costs. The German experience shows that the reduction in energy consumption can be obtained through innovative solutions (cogeneration, audits, self-consumption, etc.), which can, thus, reduce greenhouse gas emissions (Czarnitzki et al., 2020). A project to reduce greenhouse 
gas emissions from the Tunisian industry is carried out in partnership between GIZ and the National Agency for Energy Management (ANME, 2019). This project aims to promote new energy efficiency methods and technologies to carry out specific energy diagnostics within several industrial companies to select practical actions to generalize them. The use of this technology saves resources and reduces greenhouse gas emissions.

Throughout the debate, it becomes clear that there is a paucity of literature on detailed empirical findings of industrial sector carbon emissions and their potential sources, particularly in Tunisia. Therefore, we employ a robust multivariate time series VAR methodology to primarily investigate the dynamic connections of influencing drivers of carbon emission from Tunisia's industrial sectors throughout 2000-2018. To this end, our research is unique and contributes to the existing body of knowledge in the following ways. The undertaking econometric technique has the advantage of capturing parameter variation over time since it is assumed that every variable in the research is a linear function of it and other variables' past lag values. So, it helps to restore the study's dynamic system and provides reliable factual insights on the dynamic relationship between factors. In this context, Evangélique (2020) stated that the VAR model increases the credibility of economic policies that are primarily designed based on the findings of this methodology. The potential benefits of VAR modeling can be summarized as follows: (i) a priori restrictions (endogenous and exogenous variables are known automatically), (ii) arbitrary causal structure (direction of causality between variables not or poorly identified), and (iii) inadequate treatment of expectations. Hence note that, unlike the simultaneous equation system, which suffers from identification problems, autoregressive vector modeling removes the constraints associated with identifying structural equations, making it less restrictive than simultaneous equations.

To disregard the notion of simultaneity effects between variables and the shift of all endogenous variables to exogenous ensures that the VAR equations are correctly identified, adjusted, and adapts to changes in the socio-economic environment, such as shocks. Thereupon, our research will provide more robust and reliable insights to regulators, allowing them to form effective policies to limit the harmful effects of the different factors on industrial carbon emissions while promoting those initiatives that reduce $\mathrm{CO}_{2}$ emissions.

The paper's remaining contents are laid out as follows: Section 2 discusses the econometric technique used in the study. The empirical findings and discussion are presented in Section 3. Lastly, the conclusion and policy recommendations are shown in the final section. 


\section{Econometric Methodology}

\subsection{VAR Model}

Since we analyze the impact of the lag phase of a described variable on its own or explanatory variables, it is relatively hard to examine the dynamic relationship while using generic simultaneous equations model. As the variables must be specified as endogenous or exogenous variables in generic simultaneous equations, and every so often, they ignore certain critical lag variables. All variables are treated as endogenous in the VAR model, diminishing the incorrectness caused by subjective patterns in the model (Valipour et al., 2013). The Vector Autoregressive (VAR) model was introduced by Sims (1980) and is used in forecasting, structural inference, and policy analysis (Stock \& Watson, 2001). A first plus of the VAR model makes it possible to apprehend the dynamic behavior of variables linearly dependent on the past. The VAR model makes it possible to explain and analyze the evolution of a series by considering the connections between many variables. The second advantage of VAR is that it avoids having to decide situations, which are the exogenous and endogenous variables of the model, as it only includes endogenous variables. The third benefit is that the VAR model is an empirical and form of linear dynamic model with having several equations. Each equation denotes a linear relationship where a variable is expressed as a combination of its own past values and the past values of other variables. All of these model variables are endogenous. Each equation is completed by an error term which is either endogenous or exogenous. Existing research has found a plethora of dynamic correlations amid $\mathrm{CO}_{2}$ emissions and the mechanisms that drive them. Therefore, the VAR model is used to examine the dynamic impact of Tunisia's $\mathrm{CO}_{2}$ emissions driving elements.

The mathematical expressions of the general VAR $(\mathrm{P})$ model are as follows:

$$
y_{t}=A_{1} y_{t-1} \ldots \ldots \ldots+A_{p} y_{t-p}+B x_{t}+\varepsilon_{t}
$$

Where $y_{t}$ is a $k$ vector of endogenous variables, $x_{t}$ is a $d$ vector of exogenous variables, and $A_{1} \ldots \ldots \ldots \ldots A_{p}$ and $B$ are matrices of coefficients to be estimated, and $\varepsilon_{t}$ is a vector of innovations that may be contemporaneously correlated with each other but uncorrelated with their own lagged values and uncorrelated with all right-hand-side variables.

The VAR model assumes that the dynamic effects are the same in the $\mathrm{k}$ regions and the interregional effects are absent. Indeed, there are two ways of including interregional effects. The first way is to introduce one or more variables called shifted variables into the model. The second 
way is to specify a spatial process for the errors. For example, we can assume that errors follow an autoregressive process. However, in a VAR, there are no lagged variables. The error terms are uncorrelated white noise (in a forecasting model) or correlated shocks (in a structural model). The VAR model has a basic flaw: the longer the lag period, the more parameters must be estimated, and the smaller the degrees of freedom (Michieka et al., 2013). A balance between the degree of freedom and the lag periods must be found. The basic rule is to choose lag periods when both the the Akaike Information Criterion (AIC) and Swartz Criteria (SC) statistical values are the lowest. The equations could be expressed as follows for both:

$$
\begin{aligned}
& A I C=2 \mathrm{l} / \mathrm{n}+2 \mathrm{k} / \mathrm{n} \\
& S C=2 \mathrm{l} / \mathrm{n}+\mathrm{k} \log \mathrm{n} / \mathrm{n}
\end{aligned}
$$

The number of parameters to be estimated is given by $\mathrm{k}=\mathrm{m}(\mathrm{qd}+\mathrm{pm})$. The sample size is $\mathrm{n}$, and calculated by using the formula below.

$$
l=-\frac{\mathrm{nm}}{2}(1+\log 2 \pi)-\frac{\mathrm{n}}{2} \log \left[\operatorname{det}\left(\sum_{t} \hat{\varepsilon}_{t} \hat{\varepsilon}_{t}^{\prime} / n\right)\right]
$$

When calculating quantitative parameters of the population by using sample statistics, the degree of freedom is freely changing variables or the number of independents in the sample (Hu et al., 2015). The evaluating equations have fewer degrees of freedom since the VAR model has more factors and greater lag periods. With constraints on panel data, we thoroughly examine the range of parameters and lag periods in this article to assure estimation robustness. We believe that the degree of freedom in VAR enables an accurate estimation to achieve the study's aims. This assumption is based on our hands-on experience synced with other researchers working on similar challenges.

\subsection{Stationary Test}

The sequences of the immense majority of variables of economics are not stable. So, the sample data must be stationary in general for an econometric model to work. As a result, the time series must be transformed to a stationary sequence before undertaking a simulation study. Otherwise, the projected parameters would be skewed, making it impossible to explain the actual model adequately. The unit root test is the most common way of ensuring that a sequence is data stationarity. The multiple widely utilized test technique checks data stationarity as we have taken the Augmented Dickey-Fuller (ADF) test in this study. The ADF test avoids the effects of higher-order Cointegration by including a lagged difference term for the dependent variable yt in 
the equation. The ADF test is a parametric test based on the estimation of an autoregressive process. The general ADF model is written as follows:

$$
\Delta \ln y_{t}=\alpha+\beta_{t}+\delta \ln y_{t-1}+\sum_{i=1}^{k} \beta_{i} \ln y_{t-i}+\varepsilon_{t}
$$

The following assumption then tested

$$
H_{0}: \delta=0, H_{0}: \delta<0
$$

Where, $\alpha, \beta$ and $\delta$ are coefficients; $\varepsilon_{t}$ is a residual term, and $k$ is the lag length, which turns the residual term into a stochastic variable.

Dickey and Fuller (1981) consider three basic models: model without constant nor deterministic tendency, the model with constant without deterministic tendency, and model with constant and deterministic tendency. From these equations, we test the null hypothesis of unit root against the alternative hypothesis of no unit root. The application of the ADF test requires the selection of the number $\mathrm{p}$ of delays.

\subsection{Impulse response function}

The lag structure of the VAR model always passes the interference influence towards other variables. Because interference terms are correlated for the same period, a single shock in the VAR model would influence multiple interference terms simultaneously. The model's standard analytical approach is the impulse response function, which may look at the impact of a shock on all endogenous determinants in the present and upcoming periods. As a result, the impulse response function has been applied as an essential investigation technique. The following is the econometric equation of impulse response function.

$$
\begin{aligned}
I\left(n / q, I I_{t-1}\right)= & E\left(y_{t-n} \mid e_{t}=q, e_{t+1}=e_{t+2}=\ldots e_{t+n}\right. \\
& \left.=0, I I_{t-1}\right)-y_{t-n} \mid e_{t}=0, e_{t+1}=e_{t+2}=\ldots \ldots . e_{t+n} \\
& \left.=0, I I_{t-1}\right) \quad n=1,2,3 \ldots \ldots
\end{aligned}
$$

As $\mathrm{q}$ is the shock vector, $I I_{t-1}$ is the time information set $t . I\left(n j q, I I_{t-1}\right)$ is the difference in the functioning of two similar systems, which has clear economic implications. However, the states of the two systems are identical before time $t$. From $t+n$, the first system is subjected to shock with an influence strength of q. The reference system, which receives no shocks between $t$ and $t+$ 
$n$ times is the second system. The impulse response function in linear models takes the following form:

$$
I\left(n / q, I I_{t-1}\right)=E\left(y_{t-n} \mid e_{t}=q, I I_{t-1}\right)-E\left(y_{t-n} \mid e_{t}=0, I I_{t-1}\right) n=1,2,3, \ldots \ldots .
$$

Such as, future interference has no bearing on the impulse response function of linear models. In case the VAR model is stationary in equation 11, the following equations hold as:

$$
\begin{gathered}
y_{t}=v+A_{1} y_{t-1} \cdots \ldots+A_{p} y_{t-p}+\mu_{t}, \quad t=0, \pm 1, \pm 2 \ldots \ldots \\
\left(l_{M}-A_{1} L-A_{2} L^{2}-\cdots A_{p} L^{p}\right)^{-1}=l_{M}+F_{1} L-F_{2} L^{2} \ldots \cdots \cdots
\end{gathered}
$$

$L$ stands for the lag operator. Matrix $F_{n(M \times M)}$ has the following general formula:

$$
F_{n}=\sum_{l-1}^{p} A_{1} F_{n-1} \quad n=1,2,3, \ldots \ldots
$$

The primary value is

$$
F_{0}=l_{M}, F_{-1}=F_{-2}=\cdots=F_{-p+1}=0
$$

Consequently, the VAR model can be stated as follows:

$$
y_{t}=\mu_{t}+e_{t}+F_{1} e_{t-1}+F_{2} e_{t-2}+\cdots
$$

Where $\mu_{t}=Q x_{t}+F_{1} Q x_{t-1}+F_{2} Q x_{t-2}+\cdots$. If $q=i_{i}$ is the unit response function, equation 9 can be modified as:

$$
I\left(n / i_{i}, I I_{t-1}\right)=F_{n} i_{i}=\frac{d y_{t+n}}{d e_{t i}} \quad n=1,2,3, \ldots \ldots
$$

For instance, if the strength of impact is equal to the standard deviation, which is $q=s_{i} i_{i}$. In that scenario, equation 7 again could be altered as follow:

$$
I\left(n / s_{i} i_{i}, I I_{t-1}\right)=s_{i} F_{n} i_{i}=s_{i} \frac{d y_{t+n}}{d e_{t i}} \quad n=1,2,3, \ldots \ldots
$$

It can be observed the positive impact strength of impulse response.

\subsection{Model Specification and Description of Data}

Before the regression analysis, this study first describes the trend in the level of urbanization, GDP per capita, energy efficiency, the energy consumption of natural gas, and $\mathrm{CO}_{2}$ emissions in the Tunisian industrial sector. Based on the analysis of the various determining factors of $\mathrm{CO}_{2}$ emissions in the industrial sector, the econometric model is established as follows:

$$
C O_{2 t}=f\left(G D P_{t}, U R B_{t}, E C_{t}, E E_{t}\right)
$$

$$
L N C O_{2 t}=\beta_{0}+\beta_{1} L N G D P+\beta_{3} L N U R B_{t}+\beta_{4} L N E C_{t}+\beta_{5} L N E E_{t}+\varepsilon_{t}
$$


274 Where $\mathrm{CO}_{2}$ is the total $\mathrm{CO}_{2}$ emission in the industrial sector, GDP denotes economic development 275 level measured in real per capita GDP, URB means urbanization, EC signifies energy consumption 276 of natural gas of the industrial sector and EE represents energy efficiency. $\mathrm{CO}_{2}$ is expressed in 277 metric tons, GDP is measured at constant 2010 US\$, URB expressed as a percentage of urban 278 population from the total population, EC is defined in terms of (ktoe), and EE is calculated as GDP 279 divided by total energy consumption that measured at the constant 2010US\$ per 1000toe.

280 Real GDP is obtained from the World Bank (2020). The raw energy consumption of natural gas in 281 the industrial sector and $\mathrm{CO}_{2}$ emission were obtained from GIZ (2019) and National Agency for 282 Energy Conservation (2018). The raw data of urbanization was from the National Institute of 283 Statistics (NIC, 2019). All data is converted to natural logarithms. Figure 1 shows the evolution of 284 the five variables over the period studied. Descriptive statistics for the five series are given in Table 2851.

286 Table 1. Descriptive statistics.

\begin{tabular}{llllll}
\hline & $\mathrm{LCO}_{2}$ & LEC & LEE & LGDP & LURB \\
\hline Mean & 7.494567 & 7.063834 & 3.686338 & 8.245977 & 4.581796 \\
Median & 7.493874 & 7.154144 & 3.688879 & 8.299593 & 4.574711 \\
Maximum & 7.644441 & 7.467537 & 4.941642 & 8.391259 & 6.228511 \\
Minimum & 7.401842 & 6.541510 & 2.302585 & 8.006960 & 3.135494 \\
Std. Dev. & 0.070703 & 0.334692 & 1.122359 & 0.131066 & 1.141361 \\
Skewness & 0.718736 & -0.422397 & -0.174456 & -0.638364 & 0.291660 \\
Kurtosis & 2.887512 & 1.688099 & 1.331937 & 1.914975 & 1.543617 \\
\hline
\end{tabular}




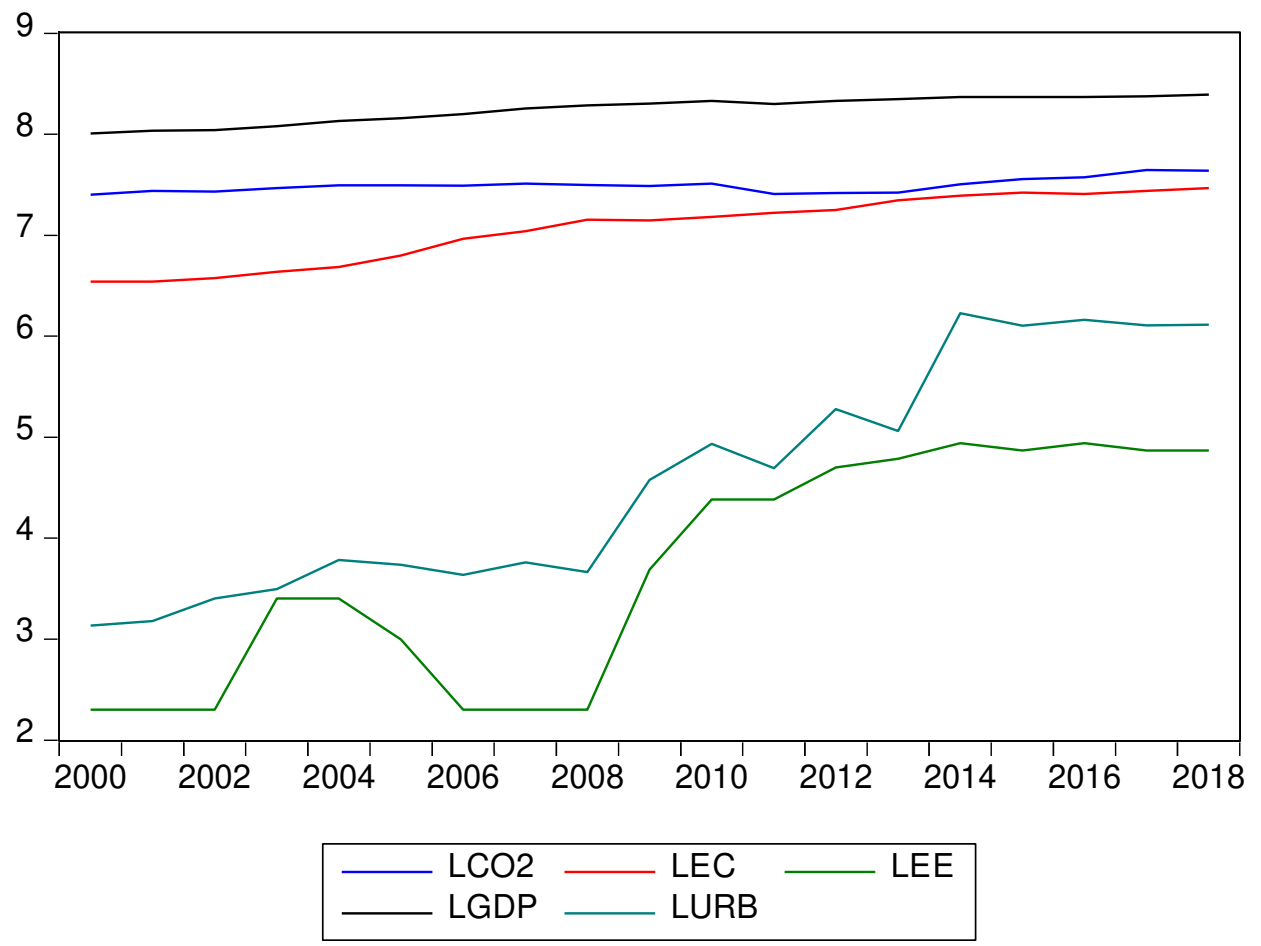

Fig.1. the evolution of the five series expressed in natural logarithms.

\section{Empirical Results and Discussion}

293 We test for the existence of unit roots of the five variables. Table 2 shows the results of the ADF 294 tests. The results show that the series is not stationary in level but stationary in the first difference. 295 Thus, all the studied variables are integrated of order one (I (1)) and can proceed to a cointegration 296 test.

297 Table 2. Results of the stationary test using the ADF test.

\begin{tabular}{llll}
\hline Variables & Level & First difference & Verdict \\
\hline $\mathrm{LCO}_{2}$ & -0.673359 & -3.898204 & $\mathrm{I}(1)$ \\
LEC & -1.231805 & -2.866368 & $\mathrm{I}(1)$ \\
LURB & -0.618106 & -5.993987 & $\mathrm{I}(1)$ \\
LGDP & -2.328766 & -3.047814 & $\mathrm{I}(1)$ \\
LEE & -1.023273 & -3.104839 & $\mathrm{I}(1)$ \\
\hline
\end{tabular}

\subsection{Johansen Cointegration tests}

300 The Cointegration test allows specifying long-term stable relationships between variables. In the 301 literature, various approaches are used to determine the number of Cointegration relationships, 302 including the Engle-Granger (1987) and Johansen (1991) approach. The first one is based on the 
Dickey-Fuller unit root tests, and the second is based on two statistics: the trace test and the eigenvalue test. The Engle-Granger approach makes it possible to obtain only one Cointegration relation, while Johansen allows distinguishing several Cointegration vectors. In this work, we adopted the Johansen approach. The Johansen Cointegration rank test results for $\mathrm{LCO}_{2}, \mathrm{LEC}$, LEE, LGDP, and LURB are given in Table 3. Both of the two tests have rejected the null hypothesis at the 5\% significance level and confirmed Cointegration between these economic variables. Table 3.Unrestricted Cointegration Rank Test (Trace)

* denotes rejection of the hypothesis at the 0.05 level

\begin{tabular}{lllll}
\hline $\begin{array}{l}\text { Hypothesized No. } \\
\text { of CE(s) }\end{array}$ & Eigenvalue & Trace Statistic & 0.05 Critical Value & Prob.** \\
\hline None $*$ & 0.996703 & 151.4075 & 69.81889 & 0.0000 \\
At most $1 *$ & 0.813309 & 54.25557 & 47.85613 & 0.0111 \\
At most 2 & 0.571450 & 25.72442 & 29.79707 & 0.1372 \\
At most 3 & 0.449819 & 11.31949 & 15.49471 & 0.1926 \\
At most 4 & 0.066061 & 1.161857 & 3.841466 & 0.2811 \\
\hline
\end{tabular}

**MacKinnon-Haug-Michelis (1999) p-values

Table 4. Unrestricted Cointegration Rank Test (Maximum Eigenvalue)

\begin{tabular}{lllll}
\hline $\begin{array}{l}\text { Hypothesized No. } \\
\text { of CE(s) }\end{array}$ & Eigenvalue & Trace Statistic & 0.05 Critical Value & Prob.** \\
\hline None $*$ & 0.996703 & 97.15190 & 33.87687 & 0.0000 \\
At most 1* & 0.813309 & 28.53114 & 27.58434 & 0.0377 \\
At most 2 & 0.571450 & 14.40493 & 21.13162 & 0.3327 \\
At most 3 & 0.449819 & 10.15764 & 14.26460 & 0.2018 \\
At most 4 & 0.066061 & 1.161857 & 3.841466 & 0.2811 \\
\hline
\end{tabular}

* denotes rejection of the hypothesis at the 0.05 level

**MacKinnon-Haug-Michelis (1999) p-values

\subsection{VAR model}

This section uses the VAR model to study the impacts of different variables on the dependent variable in the industrial sector due to the varied lag period. In other words, the duration of the lag period (p) can be chosen, depending on the real correlations between variables.

\subsubsection{The optimal lag order analysis}


321 The appropriate selection of the delay period for the VAR model is essential because long delay

322 structures can reduce the error term's autocorrelation and lead to an inefficient model. In this study,

323 we choose a shift of 2 as dictated by the log-likelihood ratio (LogL), AIC, SC, the sequential

324 modified LR test statistic (LR), FPE (final prediction error), and HQ information criterion

325 (Hannan-Quinn) (Table 5).

326 Table 5. Lag selection criteria

\begin{tabular}{lllllll}
\hline Lag & Log L & LR & FPE & AIC & SC & HQ \\
\hline 0 & 51.86978 & NA & $2.77 \mathrm{e}-09$ & -5.514091 & -5.269029 & -5.489732 \\
1 & 139.7718 & 113.7555 & $1.99 \mathrm{e}-12$ & -12.91432 & -11.44395 & -12.76817 \\
2 & 196.5120 & $40.05195 *$ & $1.39 \mathrm{e}-13 *$ & $-16.6484 *$ & $-13.9527 *$ & $-16.3805^{*}$ \\
\hline
\end{tabular}

327 Note: * indicates lag order selected by the criterion.

$328 \quad$ 3.3.2 VAR specifications and estimates

329 Table 6. Vector autoregressive estimates.

\begin{tabular}{llllll}
\hline LCO2(-1) & -0.119871 & LGDP(-1) & -0.670769 & LEE(-1) & 0.024242 \\
& $(0.73680)$ & & $(1.33971)$ & & $(0.03909)$ \\
& {$[-0.16269]$} & & {$[-0.50068]$} & & {$[0.62021]$} \\
LCO2(-2) & 1.167633 & LGDP(-2) & $\begin{array}{l}2.344353 \\
(0.67199)\end{array}$ & LEE(-2) & -0.023967 \\
& {$[1.73757]$} & & $(1.31432)$ & & $(0.04862)$ \\
LEC(-1) & 1.168651 & LURB(-1) & {$[-1.78369]$} & & {$[-0.49296]$} \\
& $(0.47847)$ & & $(0.095960$ & C & 16.87692 \\
& {$[2.44245]$} & & {$[1.12950]$} & & {$[5.23678)$} \\
LEC(-2) & 0.136733 & LURB(-2) & -0.028481 & S.E. equation & 0.037357 \\
& $(0.45625)$ & & $(0.06961)$ & & \\
R-squared & 0.891035 & Log likelihood & 40.61318 & F-statistic & 4.906353 \\
Adj. R-squared & 0.709427 & Mean dependent & 7.503361 & Akaike AIC & -3.483904 \\
Sum sq. resids & 0.008373 & S.D. dependent & 0.069303 & Schwarz SC & -2.944766 \\
\hline
\end{tabular}

330 Note: standard errors in ( ) and t-statistics in [ ].

331 In order to check if the form of the model is correct or not, we perform a robustness test on the

332 VAR model. As can be seen in Figure 2, all characteristic roots of the VAR model fall within the 333 unit circle, indicating that the model estimation results are robust. 


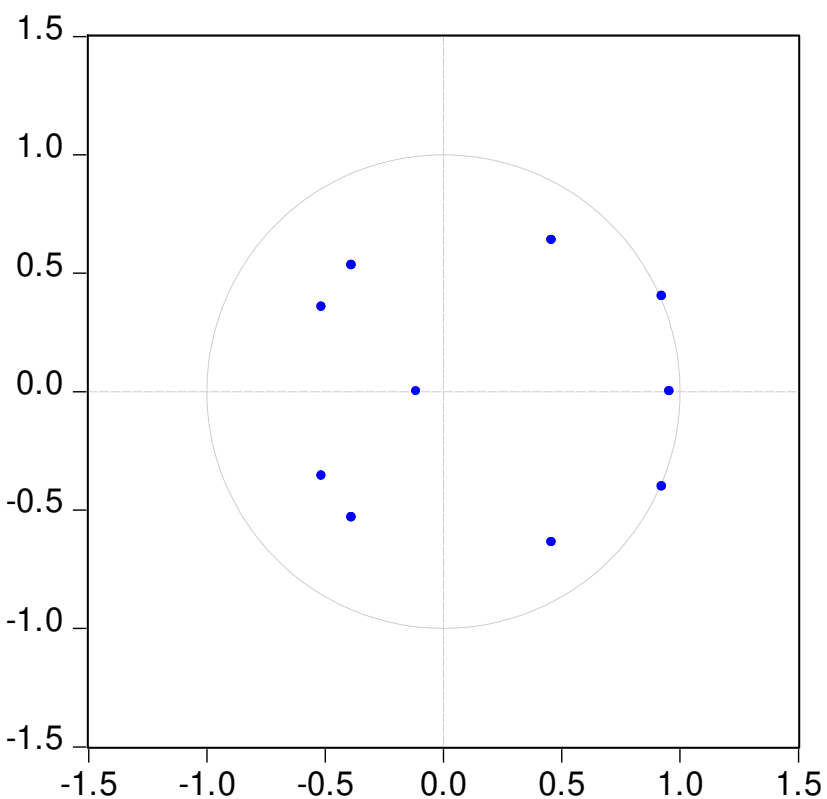

Fig. 2. VAR roots of characteristic polynomial.

\subsubsection{Impulse response functions}

In this section, the impulse response functions associated with the estimated VAR model are used to study the impacts of innovations in the explanatory variables. This methodology is very efficient and plays an imperative role in identifying shocks in model variables and measuring the impressions of such shocks. Figure 3 shows the responses of $\mathrm{CO}_{2}$ emissions from the industrial sector to fluctuate in the short and long term.

$\mathrm{CO}_{2}$ emissions in the industrial sector show a positive response to the energy consumption fluctuation in the short-term by reaching equilibrium, and then it displays a negative response (Figure 3). This indicates that energy consumption increases the $\mathrm{CO}_{2}$ emissions from the industrial sector, while energy-saving technologies will remain fixed in the short term. Given the pressures of climate change, companies will increase R\&D investments in energy-saving technologies such as hybrid, solar, and wind power plants. In the long term, energy consumption seems to drop down which helps to mitigate the $\mathrm{CO}_{2}$ emissions level due to improved technologies. 
Response of LCO2 to LEC

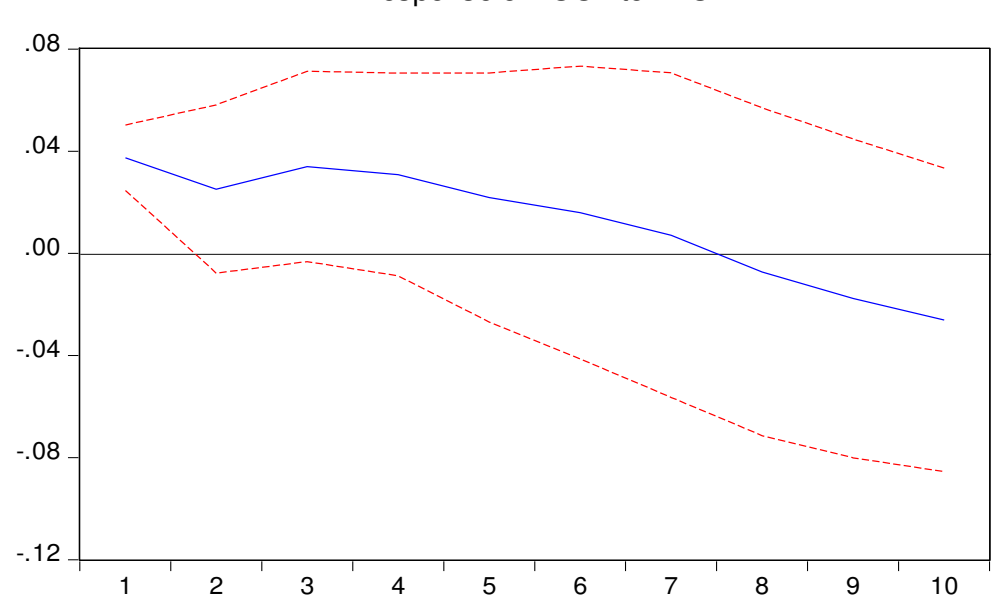

Fig.3 Response of $\mathrm{CO}_{2}$ emission to energy consumption

Tunisia has a set of measures for the development of renewable energies. It is becoming an international pole of industrial production, as is the Tunisian solar plan (Ben Jebli \& Ben Youssef, 2015). A planned installed renewable energy capacity of 3,815 MW is planned for 2030, aiming to help reduce its greenhouse gas (GHG) emissions by $41 \%$ in all sectors in order to decrease carbon intensity from levels 2010 (Mahlooji et al., 2020). Tunisia aims to achieve $30 \%$ renewable electricity production in its electricity mix by 2030, reducing the consumption of fossil fuels. A large part of the renewable energy installed comes from wind power and solar photovoltaic (PV) (UNDP, 2014). The country has also launched the BIOSOL project (Development and demonstration of a hybrid system for the gasification of biomass CSP (concentrated solar energy)) financed by the European program ERANETMED ("BIOSOL - Solar CSP hybrid gasification system of biomass boiler", 2018). It targets to integrate a prototype biomass gasification boiler in an existing CSP plant in Tunisia. Thus, the effect of the energy consumption of natural gas on $\mathrm{CO}_{2}$ emissions changes from a negative impact to a positive. This means that optimizing the energy consumption structure and integrating renewable energies is essential to reduce $\mathrm{CO}_{2}$ emissions in the industrial sector.

Figure 4 demonstrates the response of $\mathrm{CO}_{2}$ emissions to urbanization. $\mathrm{CO}_{2}$ emissions from the industrial sector show an adverse reaction to short-term urbanization, which will decrease over time. It indicates that in the long run, many residents have migrated to urban areas, leading to an increase in the urban population. Energy-intensive lifestyles due to high incomes lead to increased $\mathrm{CO}_{2}$ emissions. However, with improvements in energy-saving technologies and long-term environmental awareness, the carbon intensity of urbanization would gradually decrease. 


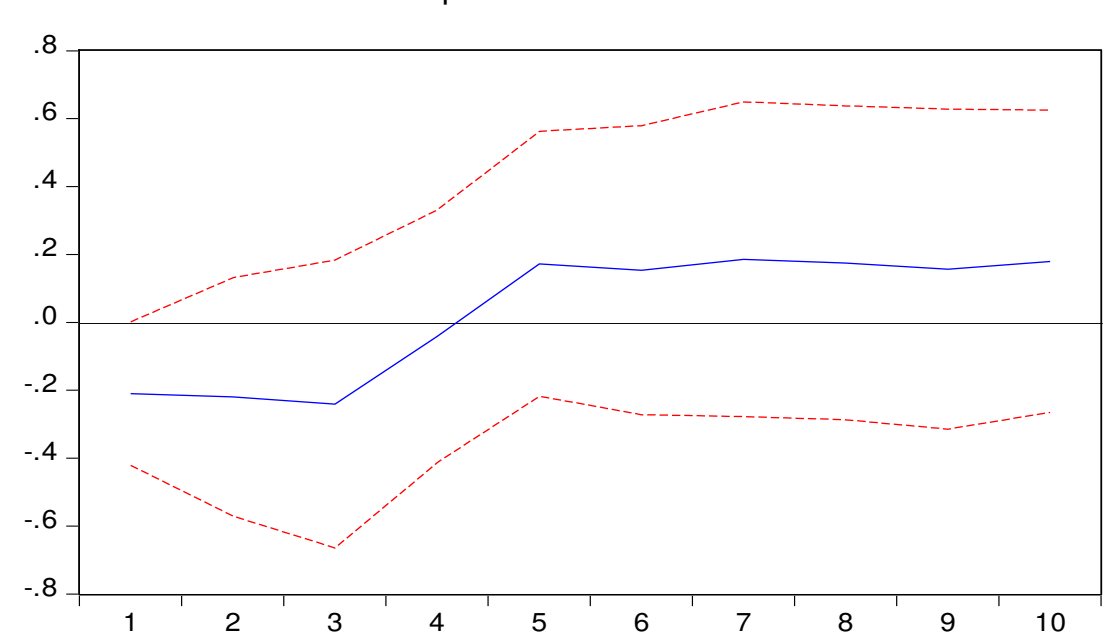

FIG.4. Response of $\mathrm{CO}_{2}$ emission to urbanization

374 Fig. 5 expresses if there is a standard deviation shock on economic growth, the $\mathrm{CO}_{2}$ emission has

375 a positive response in the short run but a negative response in the long run. It confirms the EKC 376 (Environmental Kuznets Curve) hypothesis, suggesting that economic development follows an 377 inverted "U-shaped" pattern in relation to $\mathrm{CO}_{2}$ emissions.

\section{Response of LCO2 to LGDP}

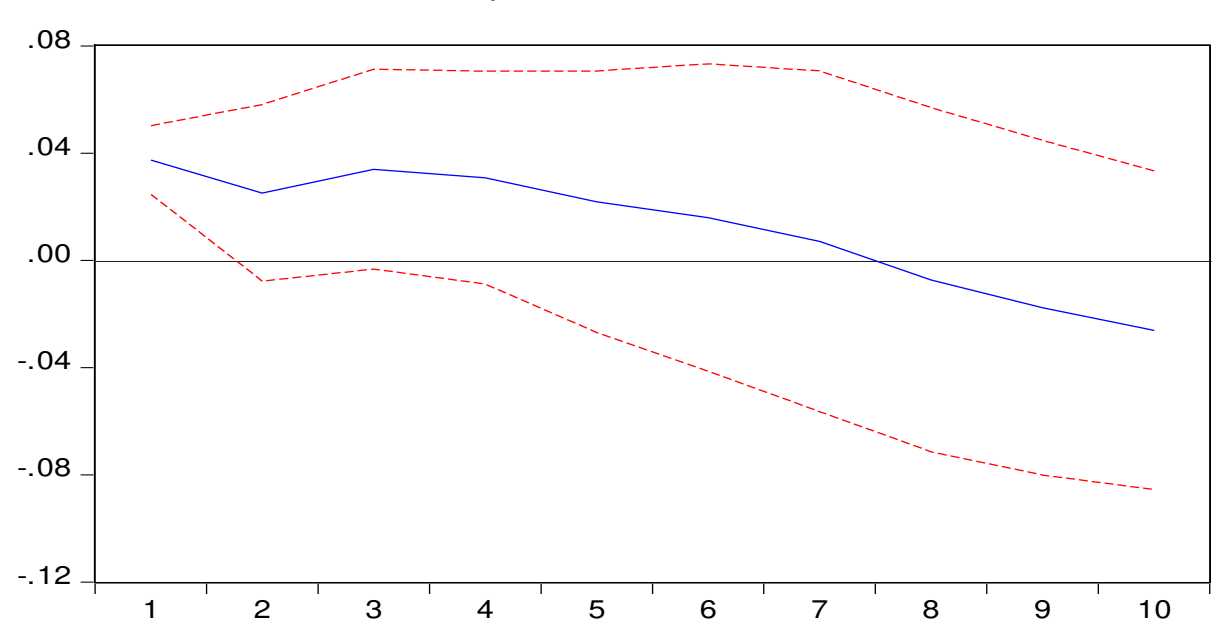

Fig.5. Response of emission $\mathrm{CO}_{2}$ to GDP

$\mathrm{CO}_{2}$ emission in the industrial sector displays a positive response to energy efficiency in the short term and a negative response in the long run (Figure 6), which means the energy efficiency plays

382 a key role in sinking long-run $\mathrm{CO}_{2}$ emissions. Tunisia has launched energy efficiency measures in 383 the industrial sector and the creation of 3 taskforces:

384 Such as Working group to help large industrial energy users save energy; Task Force on natural gas to encourage the expansion of gas use in industry; Strength to work on cogeneration to achieve 
cogeneration goals and to work with industrial companies to assist in the development and implementation of projects;

The energy efficiency industrial program contributed to energy savings amounting to 1,616 ktep, i.e., an annual average of 160 ktep per year, representing a $10 \%$ reduction in the annual consumption of the industrial companies concerned by the program (320 companies). Therefore, energy efficiency is vital in reducing $\mathrm{CO}_{2}$ emissions.

Response of LCO2 to LEE

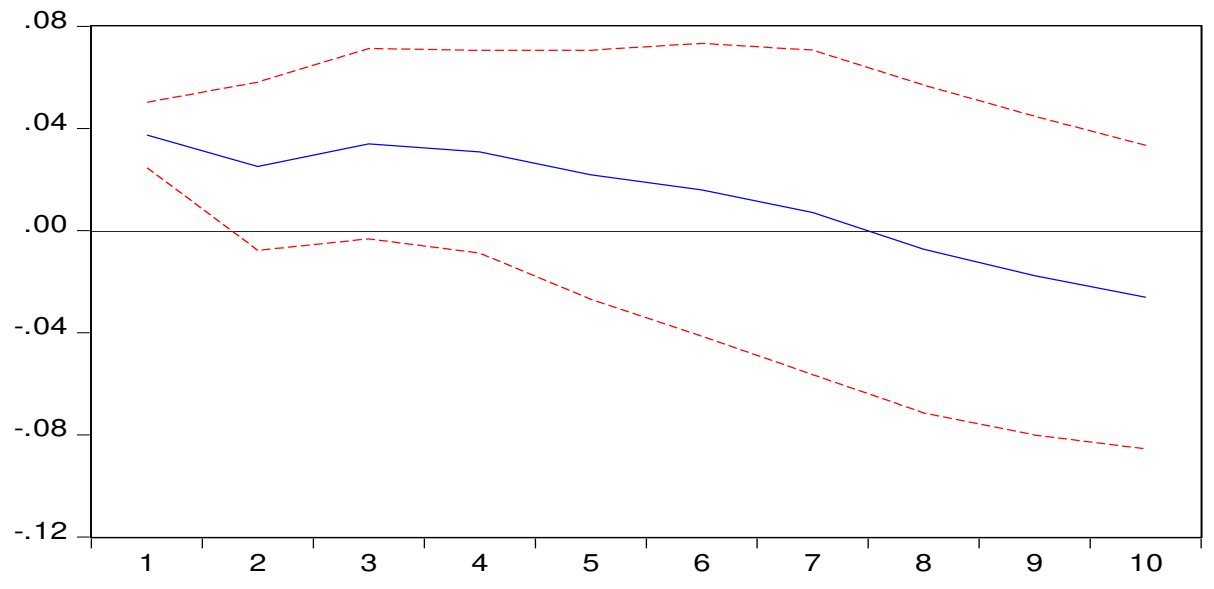

Fig.6. Response of $\mathrm{CO}_{2}$ emission to energy efficiency

\section{Conclusions and policy implications}

Using time series data from 2000 to 2018, this paper explored the driving forces of reducing the potentials of $\mathrm{CO}_{2}$ emissions in Tunisian's industrial sector by consideration of dynamic changes within the VAR model. The results indicate that energy efficiency plays a dominant role in decreasing $\mathrm{CO}_{2}$ emissions. Energy consumption and GDP have a significant effect on $\mathrm{CO}_{2}$ emissions due to large-scale population movements and industrial structure transformation. Urbanization was found to produce a negative impact in the short term and positively impact the long run. The findings are essential for Tunisian policymakers to pay close attention to since this study complements existing literature.

The first observation is that improving energy efficiency is the first contributor to the variation in $\mathrm{CO}_{2}$ emissions. The government should put policy measures to reduce energy consumption and $\mathrm{CO}_{2}$ emissions in the industrial sector. The officials must overcome the obstacles for investors to develop sustainable markets that encourage Tunisia's energy efficiency and savings. The government also needs to improve the competitiveness of industrialists by reducing production costs linked to high energy consumption. Energy efficiency measures have been identified in 
particular: 1) Strengthening the energy audit programs related to the industrial sector of Tunisia by improving the quality of energy efficiency programs. 2) Strengthening the role of energyproviding companies by assisting them with new financing mechanisms. 3) Establish an information system on energy efficiency based on relevant indicators that allow continuous evaluation of energy efficiency policy in this sector.

The second observation is that urbanization has an effect on $\mathrm{CO}_{2}$ emissions from the industrial sector. This is mainly because urbanization leads to an increase in the use of vehicles, which has favored the rapid development of industries related to automobile construction, thus increasing energy consumption and $\mathrm{CO}_{2}$ emissions. In order to reduce $\mathrm{CO}_{2}$ emissions, the government must develop a hybrid and electric public transport system and optimize the location of urban industrial zones linked to the intensive use of transport.

The third observation is that the energy consumption of natural gas has a positive effect in the short term and a negative effect in the long run. The government needs to quickly control natural gas consumption by developing and investing in new energy-saving technologies. The management of natural gas should discourage residents from consuming less and encourages them to shift to solar energy, biogas, and wind power. The government can also design a reasonable incentive and sanction mechanism to develop an appropriate system to guide the rational development and use of natural gas resources.

The fourth finding is that economic growth has a positive effect in the short run but a negative effect in the long run. Tunisia's economic growth depends on the industrial sector, especially energy-intensive heavy industries containing raw iron and steel machinery manufacturing, nonferrous metals, and petrochemical industries. These industries consume a high amount of energy and emit high GHG gases; as a result, they polluted the environment, water, and haze. Therefore, the government must optimize the industrial structure by developing a modern manufacturing technique for industries to adopt; otherwise, impose heavy fines on those not being taking action according to the government's reforms.

Moreover, the vigorous development of new strategic industries is essential for improving new energy technologies and expanding the new energy industry. Hence, the government should optimize the investing environment to attract international high-tech manufacturing companies and develop technology-led strategic initiatives for industries. 
440 Ethical Approval: This study follows all ethical practices during writing.

441 Consent to participate: Not Applicable

442 Consent to publish: Not Applicable

443 Authors Contribution: Muhammad Ramzan- Introduction, methodology, Data Analysis 444 interpretations, conclusion and policy implications. Hafiz Arslan Iqbal- Introduction and Editing.

445 Besma - Main theme, Data Collection. Buhari-Supervision

446 Funding: This study received no specific financial support.

447 Competing Interests: The authors declare that there are no conflicts of interest regarding the 448 publication of this paper.

449 Availability of Data: The datasets used and/or analysed during the current study are available 450 from the corresponding author on reasonable request

451 Transparency: The authors confirms that the manuscript is an honest, accurate, and transparent 452 account of the study was reported; that no vital features of the study have been omitted; and that 453 any discrepancies from the study as planned have been explained.

454 


\section{References}

Abid, M. (2020). The long-run and short-run effects of oil price on energy consumption in Tunisia: Evidence from structural breaks analysis. Energy Sources, Part B: Economics, Planning and Policy, 15(4), 252-277. https://doi.org/10.1080/15567249.2020.1785054

Adebayo, T.S., Ramzan, M., Iqbal, H.A. et al. The environmental sustainability effects of financial development and urbanization in Latin American countries. Environ Sci Pollut Res (2021). https://doi.org/10.1007/s11356-021-14580-4

ANME. (2019). Agence Nationale pour la Maîtrise de l'Energie,.

Ben Jebli, M., \& Ben Youssef, S. (2015). The environmental Kuznets curve, economic growth, renewable and non-renewable energy, and trade in Tunisia. Renewable and Sustainable Energy Reviews, 47, 173-185. https://doi.org/10.1016/j.rser.2015.02.049

CAIT. (2020). Greenhouse gas emissions from industry. https://www.climatewatchdata.org/dataexplorer/historical-emissions

Czarnitzki, D., Hünermund, P., \& Moshgbar, N. (2020). Public Procurement of Innovation: Evidence from a German Legislative Reform. International Journal of Industrial Organization, 71. https://doi.org/10.1016/j.ijindorg.2020.102620

Dickey, D. A., \& Fuller, W. A. (1981). Likelihood Ratio Statistics for Autoregressive Time Series with a Unit Root. Econometrica, 49(4), 1057. https://doi.org/10.2307/1912517

Dong, K., Sun, R., \& Dong, X. (2018). CO2 emissions, natural gas and renewables, economic growth: Assessing the evidence from China. Science of the Total Environment, 640-641, 293-302. https://doi.org/10.1016/j.scitotenv.2018.05.322

Du, Z., \& Lin, B. (2018). Analysis of carbon emissions reduction of China's metallurgical industry. Journal of Cleaner Production, 176, 1177-1184. https://doi.org/10.1016/j.jclepro.2017.11.178

Engle, P., Granger'Cointegration, C. W. (1987). Representation, Estimation and Testing. Econometrica.

Engo, J. (2021). Driving forces and decoupling indicators for carbon emissions from the industrial sector in Egypt, Morocco, Algeria, and Tunisia. Environmental Science and Pollution Research, 28(12), 14329-14342. https://doi.org/10.1007/s11356-020-11531-3 
modélisation à partir de l'approche VAR Structurelle. Université Evangélique En Afrique, Bukavu, RDC, 105005. https://mpra.ub.uni-muenchen.de/105005/

Farhani, S., Chaibi, A., \& Rault, C. (2014). CO2 emissions, output, energy consumption, and

Global, B. (2020). Statistical Review of World Energy - Global. British Petroleum. www.bp.com

Hu, Q., Zeng, P., \& Lin, L. (2015). The dual and degrees of freedom of linearly constrained generalized lasso. Computational Statistics and Data Analysis, 86, 13-26. https://doi.org/10.1016/j.csda.2014.12.010

IAEA. (2018). Country Nuclear Power Profiles 2018 Edition. National Energy and Mines Observatory. https://wwwpub.iaea.org/MTCD/Publications/PDF/cnpp2018/countryprofiles/Tunisia/Tunisia.htm IEA. (2020). Tracking Industry 2020. https://www.iea.org/reports/tracking-industry-2020 IRENA, IEA, \& REN21. (2018). Renewable energy policies in a time of transition. Energy Policy, November, 1-112.

Jain, P. (2018). Promoting innovative energy efficiency measures in Tunisian industry. Ministère de l'Energie, Des Mines et Des Energies Renouvelables. https://www.giz.de/en/worldwide/19529.html

KNOEMA. (2016). CO2 emissions from manufacturing industries and construction (\% of total fuel combustion). https://knoema.com/WBWDI2019Jan/world-development-indicatorswdi?tsId=2105890

Mahlooji, M., Gaudard, L., Ristic, B., \& Madani, K. (2020). The importance of considering resource availability restrictions in energy planning: What is the footprint of electricity generation in the Middle East and North Africa (MENA)? Science of the Total Environment, 717. https://doi.org/10.1016/j.scitotenv.2019.135035

Meng, M., Jing, K., \& Mander, S. (2017). Scenario analysis of CO2 emissions from China's electric power industry. Journal of Cleaner Production, 142, 3101-3108. https://doi.org/10.1016/j.jclepro.2016.10.157

Michieka, N. M., Fletcher, J., \& Burnett, W. (2013). An empirical analysis of the role of China's exports on CO2 emissions. Applied Energy, 104, 258-267. https://doi.org/10.1016/j.apenergy.2012.10.044 
NIC. (2019). National Institute of Statistics. https://knoema.com/atlas/sources/INS-TN Noreen Safdar. (2020). How do Energy Consumption, Environmental Degradation and Macroeconomic Performance Cause in Developing Countries? An Analysis. Journal of Business and Social Review in Emerging Economies, 6(3), 1189-1197. https://doi.org/10.26710/jbsee.v6i3.1388

Pachauri, K. Meyer, L. A. (2014). Climate change 2014: synthesis report. Contribution of Working Groups I, II and III to the fifth assessment report of the Intergovernmental Panel on Climate Change. Ipcc, 151.

Rapier, R. (2020). Fossil Fuels Still Supply 84 Percent Of World Energy - And Other Eye Openers From BP's Annual Review. Forbes. https://www.forbes.com/sites/rrapier/2020/06/20/bp-review-new-highs-in-global-energyconsumption-and-carbon-emissions-in-2019/?sh=7254dc8d66a 1

Song, Y., Huang, J. B., \& Feng, C. (2018). Decomposition of energy-related CO2 emissions in China's iron and steel industry: A comprehensive decomposition framework. Resources Policy, 59, 103-116. https://doi.org/10.1016/j.resourpol.2018.06.004

Søren, J. (1991). Estimation and Hypothesis Testing of Cointegration Vectors in Gaussian Vector Autoregressive Models. Econometrica, 59(6), 1551-1580.

Stock, J. H., \& Watson, M. W. (2001). Vector autoregressions. Journal of Economic Perspectives, 15(4), 101-115. https://doi.org/10.1257/jep.15.4.101

Tan, X., Li, H., Guo, J., Gu, B., \& Zeng, Y. (2019). Energy-saving and emission-reduction technology selection and $\mathrm{CO} 2$ emission reduction potential of China's iron and steel industry under energy substitution policy. Journal of Cleaner Production, 222, 823-834. https://doi.org/10.1016/j.jclepro.2019.03.133

UNDP. (2014). TUNISIA: Derisking Renewable Energy Investment - Selecting Public Instruments to Promote Renewable Energy Investment for the Tunisian Solar Plan NAMA. https://www.uncclearn.org/resources/library/tunisia-derisking-renewable-energyinvestment-selecting-public-instruments-to-promote-renewable-energy-investment-for-thetunisian-solar-plan-nama/

Valipour, M., Banihabib, M. E., \& Behbahani, S. M. R. (2013). Comparison of the ARMA, ARIMA, and the autoregressive artificial neural network models in forecasting the monthly inflow of Dez dam reservoir. Journal of Hydrology, 476, 433-441. 
https://doi.org/10.1016/j.jhydrol.2012.11.017

550 Wen, Z., Wang, Y., Li, H., Tao, Y., \& De Clercq, D. (2019). Quantitative analysis of the precise

551 energy conservation and emission reduction path in China's iron and steel industry. Journal of Environmental Management, 246, 717-729.

$553 \quad$ https://doi.org/10.1016/j.jenvman.2019.06.024

554 World Bank. (2020). World development indicators, Washington, DC: IBRD.

555 Xu, B., \& Lin, B. (2016). Assessing CO2 emissions in China's iron and steel industry: A

556 dynamic vector autoregression model. Applied Energy, 161, 375-386.

$557 \quad$ https://doi.org/10.1016/j.apenergy.2015.10.039

558 Xu, B., \& Lin, B. (2020). Investigating drivers of CO2 emission in China's heavy industry: A quantile regression analysis. Energy, 206. https://doi.org/10.1016/j.energy.2020.118159 